\title{
Concord, convergence and accommodation in bilingual children*
}

\author{
ANDREW RADFORD \\ University of Essex \\ TANJA KUPISCH \\ University of Hamburg \\ REGINA KÖPPE \\ University of Hamburg \\ GABRIELE AZZARO \\ Università di Bologna
}

\begin{abstract}
This paper examines the syntax of GENDER CONCORD in mixed utterances where bilingual children switch between a modifier in one language and a noun in another. Particular attention is paid to how children deal with potential gender mismatches between modifier and noun, i.e., if one of the languages has grammatical gender but the other does not, or if one of the languages has a ternary gender system and the other a binary one. We show that the English-Italian and French-German bilingual children in our study accommodate the gender properties of the noun to those of its modifiers in such cases, in order to ensure convergence.
\end{abstract}

\section{Overview}

This paper examines the syntax of GENDER CONCORD in (language-)mixed utterances where bilingual children switch between a (determiner or adjective) modifier in one language and a noun in another. It is organised as follows. Section 2 presents a selective review of existing work on intrasentential language mixing by bilingual speakers, noting that numerous researchers have suggested a constraint to the effect that mixing is possible only when the features of the mixed constituents match. Section 3 suggests that this feature-matching requirement has a natural Minimalist analogue in the requirement for syntactic structures to be CONVERGENT, and looks at how convergence requirements constrain mixing between modifiers and nouns. Section 4 looks at the development of bilingual children, and formulates an ACCOMMODATION HYPOTHESIS to the effect that in cases where lexical gaps or retrieval problems lead them to switch languages between modifier and noun, they overcome any potential feature mismatch between the two by accommodating the morphological features of the noun to those of its modifier. Sections 5-8 test the Accommodation Hypothesis empirically in relation to naturalistic data from bilingual (English-Italian and French-German) children whose languages have mismatching gender systems. It is found that the children accommodate the different gender systems of their two languages in three main ways, namely (i) assigning an honorary gender feature to an ungendered English noun with a gendered Italian

* We are grateful to Enam Al Wer, Harald Clahsen, and two anonymous reviewers for helpful comments on an earlier draft of this paper, and to the University of Essex for providing a small grant from its Research Promotion Fund to employ Marina Arlati to transcribe the LuCY tapes. modifier, (ii) stripping a gendered Italian noun of its gender feature when it has an ungendered English modifier, and (iii) changing the gender of a German neuter noun which has a gendered modifier from a language like French with no neuter gender. Section 8 summarises our main claims and findings.

\section{Existing work on mixing within the Principles-and-Parameters framework}

Ever since the pioneering work of Werner Leopold (1970), linguists have been fascinated by intrasentential languagemixing (hereafter, simply MIXING) by adult and child bilinguals - a phenomenon which can be illustrated by the following sentence produced by Leopold's bilingual daughter Hildegard at age 3;3 (with the two German words in bold):

(1) I can't give you any Kuss ("kiss") because I have a Schmutznase ("dirty.nose")

In the main clause, Hildegard switches between the English quantifier any and the German noun Kuss "kiss", while in the subordinate clause she switches between the English indefinite article $a$ and the German noun Schmutznase "dirty.nose". An important theoretical question which arises from mixed structures like (1) is whether there are universal constraints governing where mixing is (and isn't) permitted. In this section, we present a brief (selective) review of a number of constraintsbased accounts of mixing: see Muysken (2000) for a comprehensive review.

The development of PRINCIPLES-AND-PARAMETERS THEORY (PPT) in Chomsky (1981) gave rise to a number of attempts by linguists working within the PPT framework 
to argue that mixing is constrained by innate structural principles of Universal Grammar. An early attempt of this kind was the GOVERNMENT CONSTRAINT proposed in a (1986) paper by Di Sciullo, Muysken and Singh (=DMS), which bars mixing between a governor and an expression which it governs. Since DMS take CONTENTIVES (i.e. content words such as verbs, adjectives, nouns and prepositions) to be governors and assume a particular definition of government which takes heads to govern their complements but not their specifiers, we can informally regard their constraint as stating that mixing cannot take place between a content word and its complement. However, a number of subsequent studies (including Klavans, 1985; Clyne, 1987; Romaine, 1989; Muysken, 1990; Nortier, 1990; Stenson, 1990; Chan, 1999; Boumans, 2001; Gardner-Chloros and Edwards, 2004) pointed out that the Government Constraint wrongly predicts that mixing should not occur between verb and object - and yet verb-object switches are reported by the relevant authors to be among the most frequent types of mix.

An alternative FUNCTIONAL HEAD CONSTRAINT $(=\mathrm{FHC})$ was proposed in a (1994) paper by Belazi, Rubin and Toribio $(=\mathrm{BRT})$. This bars mixing between a FUNCTOR (i.e. a functional head like $\mathrm{C}, \mathrm{T}, \mathrm{Neg}, \mathrm{D}$ or Q) and its complement because the two must carry the same language feature. BRT noted that if inflectional morphemes are analysed as functional heads, FHC would provide a principled account of Poplack's (1980) FREE MORPHEME CONSTRAINT which bars switching between a head and an inflectional morpheme. However, the empirical basis of FHC is called into question by data from Di Sciullo et al. (1986) that show adult French-Italian bilinguals switching language between a determiner/auxiliary/complementiser and its complement, and data from MacSwan (1997) that show adult Spanish-Nahuatl bilinguals doing likewise. No less importantly, the Functional Head Constraint seems to be implausible from a conceptual point of view, in implicitly treating LANGUAGE as a grammatical feature (see Mahootian and Santorini, 1996; Köppe, 1997; MacSwan, 1999).

Chan (1999) proposed to deal with problems besetting FHC by replacing it by a HEAD SELECTION CONSTRAINT/HSC to the effect that mixing is permitted only if the selectional requirements of heads are met (i.e. if a head has an appropriate kind of complement). HSC offers the twin advantages over FHC that it does away with the need to posit that syntactic computations are sensitive to language features, and also avoids singling out FUNCTIONAL heads as subject to special constraints which other heads are not subject to. And yet, a theoretical question which arises from HSC is why the constraint should single out the SELECTIONAL properties of heads, and thereby exclude their other properties (e.g. their agreement properties, case-marking properties, and so on). After all, an auxiliary head not only needs to have an appropriate kind of complement, but also needs to agree with and case-mark its subject (in the case of subjectauxiliary switches). Such considerations suggest that a more general constraint is required.

A wide range of attempts have been made to formulate just such a more general constraint which captures the intuition that mixing is only possible between one constituent and another if there is CONGRUENCE between the two (Weinreich, 1964; Myers-Scotton, 1993; MyersScotton and Jake, 1995; Jake and Myers-Scotton, 1997; Sebba 1998), or STRUCTURAL CONSISTENCY (Lindholm and Padilla, 1978), or absence of STRUCTURAL CONFLICT (Pfaff, 1979), or EQUIVALENCE (Poplack, 1980), or STRUCTURAL INTEGRITY (Sankoff and Poplack, 1981), or CORRESPONDENCE (Joshi, 1985), or SYNTAGMATIC COHERENCE (Di Sciullo et al., 1986), or GRAMMATICAL COHESIVENESS (Meisel, 1994), or FEATURE-MATCHING (MacSwan, 1997). One problem which such accounts pose is that key concepts like STRUCTURAL INTEGRITY are often only loosely formulated (and are not standard terms which are formally defined within a specific linguistic theory), making it impossible to make (and test) precise predictions about mixing. In the next section, we investigate the possibility of providing a coherent characterisation of the intuition underlying these general claims in terms of the notion of CONVERGENCE which is a core concept of the MINIMALIST theory of syntax developed by Chomsky $(1995,1998$, 1999, 2001, 2002, 2005, forthcoming), and we go on to offer a convergence-based account of mixing in Concord structures. However, for readers who are unfamiliar with Minimalism, we begin by outlining the notion CONVERGENCE, and discuss its relevance to Concord structures.

\section{Convergence and Concord mixing}

A core idea underlying the Minimalist model of syntax developed in Chomsky (1995, 1998, 1999, 2001, 2002, 2005 , forthcoming) is that language is a perfect system of optimal design, and that grammars create structures which are designed to interface perfectly with speech and thought systems, so that (in the words of Chomsky, forthcoming, p. 2) "[l]anguage is an optimal way to link sound and meaning". One component of a grammar is a LEXICON (containing a list of all the lexical items in the language and their idiosyncratic properties), and the first step in the derivation of a sentence is to take a set of words out of the Lexicon (these constituting the LEXICAL ARRAY from which the sentence is to be constructed). The chosen words are then combined together by a series of syntactic computations (involving merger, movement and agreement operations), thereby generating a syntactic structure. This syntactic structure serves as input into two other components of the grammar. One is a SEMANTIC COMPONENT which maps the syntactic structure into a corresponding SEMANTIC REPRESENTATION: the other is 
a PF COMPONENT which maps the syntactic structure into a representation of its PHONETIC FORM, providing a phonetic SPELLOUT for each word which determines how it is pronounced. The semantic representation interfaces with systems of thought, and the PF representation with systems of speech - as shown in the diagram in (2) (from Radford, 2004, p. 9).

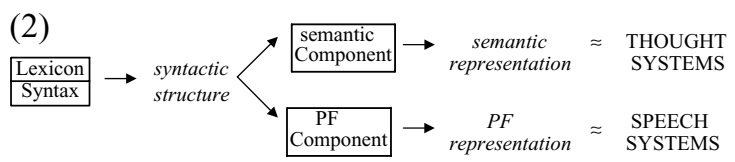

Within the Minimalist model in (2), an important constraint is that structures generated by the grammar should lead to CONVERGENCE at the interface levels - i.e. should result in semantic and $P F$ representations which are LEGIBLE by the appropriate interface system (so that the semantic representations handed over to thought systems contain only elements which contribute to determining meaning, and the PF representations handed over to speech systems contain only elements which contribute to determining phonetic form).

A key assumption made within Minimalism is that some grammatical features of lexical items enter the syntax already VALUED, whereas others enter UNVALUED. In order to ensure convergence at the PF interface, unvalued features must be assigned a value in the syntax, because unvalued features are illegible in the PF component (and will cause the derivation to crash). A second assumption made within Minimalism is that some grammatical features are INTERPRETABLE (and contribute to determining aspects of meaning), whereas others are UNINTERPRETABLE (and play no role in determining meaning). In order to ensure convergence at the semantics interface, uninterpretable features must be deleted in the syntax so that they are not inputted into the semantic component, because uninterpretable features are illegible in the semantic component (and will cause the derivation to crash). Chomsky (1998) argued that uninterpretable features can only be deleted via matching with a COMPLETE constituent (e.g. the uninterpretable person/number $\varphi$-features features on a finite auxiliary can only be deleted via agreement with a matching noun or pronoun expression carrying a complete set of person/number $\varphi$-features). Deleted features remain visible in the PF component, however.

If we suppose that adult bilinguals have two separate grammars and two separate lexicons ${ }^{1}$ and if we take the Null Hypothesis to be that the grammars of bilingual speakers are subject to the same UG principles as those of monolingual speakers (as argued es.g. in Woolford, 1983; Mahootian, 1993; and Belazi et al., 1994), we would expect the primary syntactic constraint on the

\footnotetext{
1 We shall subsequently revise the TWO LEXICONS assumption, however.
}

mixed structures produced by bilinguals to be that they should result in convergence (the only difference between monolingual and bilingual sentences being that the lexical array in a monolingual sentence comprises items from a single language, whereas that in a bilingual sentence involves items drawn from more than one). Such a condition is proposed by MacSwan (1997, 1999, 2000, 2004, 2005) and Chan (1999, 2004, 2005) for mixing in adult grammars. Let's therefore look at how convergence requirements would be expected to constrain the operation of Concord in bilingual MODIFIER+NOUN structures.

The term CONCORD is traditionally used to refer to an operation by which an adnominal adjective or determiner and a noun they modify are made to agree in respect of their shared number and gender features. It can be illustrated by an Italian structure like that below, ${ }^{2}$

(3) una buona macchina

$a_{\mathrm{F} . \mathrm{SG}} \operatorname{good}_{\mathrm{F} . \mathrm{SG}} \operatorname{car}_{\mathrm{F} . \mathrm{SG}}$

with the final $-a$ of the three words in (3) marking them as feminine singular forms. Although Concord seems to involve much the same kind of feature matching operation as Agreement, there are a number of reasons for supposing that it is a distinct operation from Agreement. Firstly, Agreement involves concomitant assignment of case to an associated nominal (i.e. noun or pronoun expression), whereas Concord does not. Secondly, Agreement and Concord may affect different types of feature: for example, in Spanish Concord involves gender but Agreement does not, and in Arabic Concord involves definiteness but agreement does not. Moreover, the two operations have different domains: e.g. agreement between a tensed auxiliary $(=\mathrm{T})$ and a nominal takes place on the T-cycle, whereas Concord between a determiner $(=\mathrm{D})$, adjective and noun takes place on the D-cycle. Finally, the two may differ in respect of whether they are associated with movement: e.g. in Italian, Agreement is often associated with movement (in that a T-auxiliary may attract a nominal it agrees with to move to become the specifier of T), whereas no such movement (e.g. of macchina "car" in front of una "a" in a structure like (3)) takes place under Concord.

Let's look first at whether convergence requirements would lead us to expect modifier-noun mixing to occur in a nominal like a good macchina car $_{\text {where an English }}$ determiner and adjective are used to modify an Italian noun. Let us suppose that the noun macchina $a_{\text {car }}$ enters

\footnotetext{
2 Abbreviations used for features throughout are as follows: $\mathrm{C}=$ Common, $\mathrm{F}=$ Feminine, $\mathrm{Gen}=$ Gender, $\mathrm{M}=$ Masculine, $\mathrm{N}=$ Neuter, Num $=$ Number, Pers $=$ Person, $\mathrm{Pl}=$ Plural, $\mathrm{Sg}=$ Singular, $\mathrm{u}=$ Unvalued. For ease of exposition, we set aside a number of technical questions here, such as which constituents carry an abstract case feature and how this is valued, and whether (as proposed by Picallo, 1991; Ritter, 1991; Cinque, 1994) nouns in Italian raise to an intermediate functional head position (e.g. Num) between D and $\mathrm{N}$.
} 
the syntax carrying an intrinsic feminine-gender feature [F-Gen], but an unvalued number feature [u-Num]: this reflects the fact that macchina $a_{\mathrm{car}}$ is inherently feminine in gender, but can be either singular or plural in number. Conversely, the English indefinite article $a$ enters the syntax with an intrinsic singular-number feature [SgNum]. Given the claim by Chomsky $(1999$, p. 2) that parametric variation is restricted to inflectional properties which are "easily detectable in data available for language acquisition", we can follow Namai (2000) in concluding that the Concord features (henceforth: C-features) found in English include number but not gender, so that both determiners and nouns carry number in English (easily detectable in contrasts like this car/these cars) but neither carries grammatical gender (since there are no nouns, adjectives or determiners which overtly inflect for gender in English, making gender undetectable on the relevant items). On similar (detectability) grounds, we can also suppose that adjectives do not carry number in English. Finally, if we follow Abney (1987) and Radford (1997) in positing that determiners are the locus of person properties in nominals (in the sense that determiners carry person, but nouns and adjectives do not), the indefinite article will also carry an intrinsic third-person feature. Given these assumptions, the relevant items in a mixed nominal like a good macchina $a_{\text {car }}$ will enter the syntax carrying the (person/number/gender) $\varphi$-features shown below (with lexical items CAPITALISED and shown in their dictionary citation form, and uninterpretable features italicised):

$$
\begin{aligned}
& \text { (4) A GOOD MACCHINA } \\
& \text { [Sg-Num] [u-Num] } \\
& \text { [3-Pers] [F-Gen] }
\end{aligned}
$$

The unvalued number feature on the noun macchina $_{\mathrm{car}}$ is valued via Concord with the article, yielding the outcome shown below:

$$
\begin{aligned}
& \text { (5) A GOOD MACCHINA } \\
& \text { [Sg-Num] [Sg-Num] } \\
& \text { [3-Pers }] \text { [F-Gen }]
\end{aligned}
$$

Since all $\varphi$-features have been valued, each of the items can be given an appropriate PF spellout, so that the resulting structure will be convergent at the PF interface. But what of convergence at the semantics interface? This requires uninterpretable features to be deleted in the syntax, so that only interpretable features are inputted into the semantic component. The number and person features on the determiner are interpretable, but the italicised number and gender features on the noun are not (its number feature being merely a copy of that on the determiner, and its gender feature being arbitrary). This means that the uninterpretable number and gender features on the noun must be deleted via agreement with a complete superordinate head. However, the uninterpretable gender feature on the noun cannot be deleted via Concord with the determiner, for the simple reason that the (English) determiner carries no gender feature to match the feminine gender feature on the Italian noun. Moreover, if (following Chomsky, 1998, p. 40) "[w]e take deletion to be a "one fell swoop' operation, dealing with the $\varphi$-set as a unit", then the uninterpretable number feature on the noun in (5) cannot be deleted either. The (italicised) undeleted uninterpretable number and gender features on the noun will thus cause the derivation to crash at the semantics interface, leading us to the more general conclusion that:

(6) Mixing between an ungendered determiner and a gendered noun leads to a crash.

Empirical support for this claim comes from the observation made by Lipski (1978), Moyer (1993), Belazi et al. (1994), and Jake, Myers-Scotton and Gross (2002) that adult Spanish-English bilinguals do not allow mixing between an ungendered English determiner and a gendered Spanish noun (as in $*$ the casa $a_{\mathrm{F} . \mathrm{Sg}}$ "the house").

Consider now what would be expected to happen in the converse situation where a bilingual speaker uses a gendered Italian modifier (e.g. an article like uN "a" or an adjective like BUONO "good") to modify an ungendered English noun like CAR. Consider, for example, whether mixing would be expected to occur in a structure such as the following:

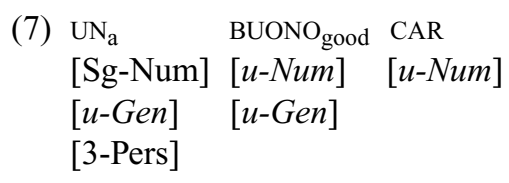

The unvalued number features on the adjective and noun can be valued as singular (and deleted) via matching with the singular-number feature on the ( $\varphi$-complete) article, so that we would expect NUMBER CONCORD to take place. However, the unvalued, uninterpretable gender features on the determiner and adjective cannot be valued by the ungendered English noun car, and the derivation will therefore crash at the PF interface (on the assumption that the PF component cannot spell out an unvalued feature). Moreover, if we suppose that feature-deletion presupposes feature valuation (in the sense that a feature cannot be deleted unless it has been valued), the uninterpretable gender features on the determiner and adjective cannot be deleted either, thereby leading to a crash at the semantics interface. Our discussion thus leads us to conclude that

(8) Mixing between a gendered modifier and an ungendered noun leads to a crash. ${ }^{3}$

3 MacSwan (2005, p.18) cites unpublished work by Moro (2001) claiming that (contrary to what we say here) convergence considerations allow mixing between a gendered (Spanish) determiner and an ungendered (English) noun. MacSwan reports (ibid.) that Moro posits that in such structures the Determiner carries person, number and gender features, while the noun carries person and number, and 
Empirical support for (8) comes from the observation made by Belazi et al. (1994, p. 229, ex. (18b)) that adult English-Spanish bilinguals do not switch between a gendered Spanish quantifier and an ungendered English noun in an expression like pocos $_{\text {few }}$ students, and from the parallel observation by MacSwan (1997, p. 245) that adult Spanish-Nahuatl bilinguals likewise do not allow switching between a gendered Spanish determiner and an ungendered Nahuatl noun.

Thus far, we have looked at how interface requirements would be expected to constrain modifier-noun mixing between gendered and ungendered languages. But this raises the question of whether such mixing would be expected to occur between two gendered languages with ASYMMETRIC gender systems - e.g. between a language like French with a binary (MASCULINE/FEMININE) gender system, and a language like German with a ternary (MASCULINE/FEMININE/NEUTER) gender system. For selfevident reasons, we should expect no problems to arise when a determiner or adjective from one language modifies a masculine or feminine noun from the other, since both languages have masculine and feminine gender. Where problems would be expected to arise is in structures like (9) below containing a German neuter noun with French modifiers:

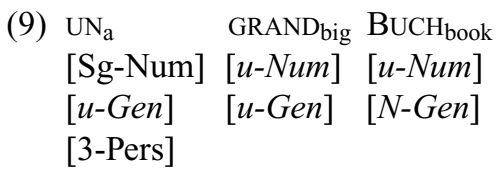

Concord on the D-cycle results in the noun valuing the unvalued gender features on the adjective and determiner as neuter, and in the determiner valuing the unvalued number features on the adjective and noun as singular. It also results in the uninterpretable number and gender features on the adjective and noun being deleted via Concord with the complete determiner: similarly, we might suppose that Concord also results in the deletion of the uninterpretable gender feature on the determiner, if gender is purely a Concord feature (and not an Agreement feature) in languages like French and German, and if a pure Concord feature like gender can be deleted via Concord with a C-complete constituent (i.e. one carrying

that "the $\varphi$-features of $\mathrm{N}$ (person and number), being included in D's $\varphi$-set, successfully value and delete D's uninterpretable features 'in one fell swoop"'. However, this analysis seems problematic in two respects. Firstly, there is no evidence that nouns carry person (e.g. they do not overtly inflect for person, and expressions like you linguists/we linguists suggest that they cannot be intrinsically third person), and if an English noun carries number alone, it will not be $\varphi$-complete and so will be unable to delete uninterpretable features on a Spanish D. Moreover, if the noun lacks gender, it will neither be able to value nor delete the (initially unvalued) gender feature on the Spanish determiner. a complete set of number/gender Concord features). If so, the uninterpretable gender feature on the determiner can be deleted via Concord with the C-complete noun, so deriving the following structure:
(10) $\mathrm{UN}_{\mathrm{a}} \quad \mathrm{GRAND}_{\text {big }} \mathrm{BUCH}_{\text {book }}$ [Sg-Num] [Sg-Num] [Sg-Num] [N-Gen] [N-Gen] [N-Gen] [3-Pers]

However, while the resulting structure will ultimately converge at the semantics interface, it crashes at the PF interface, because French has no neuter gender, and thus cannot spell out the neuter gender feature on the determiner or adjective. Accordingly, structures like (10) lead us to hypothesise that:

(11) Mixing between a gendered modifier and a noun with a language-specific gender (i.e. one which is not found in the language of the modifier) leads to a crash.

More generally, the theoretical considerations outlined in this section suggest the following three constraints on gender mixing:

\section{(12) Convergence requirements constrain mixing}

(i) between an ungendered determiner and a gendered noun $(=(6)$ above $)$

(ii) between a gendered modifier and an ungendered noun $(=(8))$

(iii) between a gendered modifier and a noun with a language-specific gender value $(=(11))$

The overall spirit of the constraints in (12) is that gender mixing is expected to be barred between a modifier and noun where this leads to a GENDER MISMATCH of some kind, because (as noted by Chomsky 1995, p. 309, ex. (108)) '[m]ismatch of features cancels the derivation'. And, as we have seen, there is some empirical evidence (from studies cited above) that such constraints hold in the grammars of adult bilinguals. But do similar constraints hold for child bilinguals? This is a question we address in the next section.

\section{Mixing in bilingual children}

There is a body of research suggesting that grammatical constraints on mixing which operate in adult grammars may be inoperative in very early child grammars. Since the relevant constraints operate on functional features (i.e. features which are associated with functional categories, such as case and agreement features) which may not have been acquired by very young children (e.g. those under two years of age), Meisel $(1989,1990,1994)$ and Köppe 
and Meisel (1995) argue that constraints on mixing do not operate in children who have immature grammars which lack the relevant functional features. The obvious implication of this for our research into gender-based constraints on mixing like those in (12) is that we should not expect to find such constraints operating until such time as bilingual children have acquired grammatical gender. Evidence from existing studies suggests that young children show extremely high gender accuracy rates - especially in languages like Italian with transparent gender marking (see Chini 1995). For instance, Pizzuto and Caselli (1992) report a gender accuracy rate of $96 \%-97 \%$ in three children acquiring Italian aged between 1;4 and 3;0. Kupisch, Müller and Cantone (2002) report a gender accuracy rate of more than $98 \%$ in the monolingual Italian child Martina between 1;7 and 2;7 and in the monolingual French child Grégoire between 1;7 and 2;7; they also report gender accuracy rates of $97 \%$ and $98 \%$ in two bilingual GermanItalian children aged from $1 ; 8$ to $3 ; 0$. German-French bilingual children appear to have rather more problems in gender marking (which is only to be expected given the opacity of French and German gender marking): for example, Kupisch et al. (2002) quantify Müller's (1994) results on gender marking in bilingual German-French children, which yield accuracy rates of $87 \%$ for Pascal between 1;9 and 2;7, 81\% for Caroline between 1;10 and $2 ; 11$ and $86 \%$ for Ivar between $2 ; 4$ and 2;11.

What our discussion above suggests is that two-yearolds (whether monolingual or bilingual) show high gender accuracy rates. Accordingly, we might expect to find evidence that when they mix languages, they will obey the gender constraints on mixing in (12) above and hence will not mix between a modifier in one language and a noun in the other if this results in a potential gender mismatch. However, since young children have only a limited vocabulary, it could be that communicative needs may sometimes force a child to switch in such structures: for instance, a Spanish-English bilingual might have to switch between (say) the Spanish indefinite article $u n_{\mathrm{a}}$ and an English noun like window if the child has not yet acquired (or is unable to retrieve) the corresponding

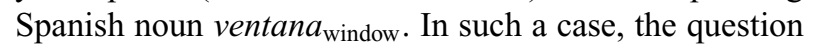
arises as to whether the child simply violates the gender constraint in (12ii) preventing mixing from taking place between a gendered Spanish modifier and an ungendered English noun, or whether - as we shall suggest here the child finds a way of resolving the potential gender mismatch. Before proceeding further, let us briefly amplify on the remarks in this paragraph.

Existing research (e.g. Volterra and Taeschner, 1978; Fantini, 1985; Genesee, 1989; Lanza, 1990, 1997; Pearson, Fernandez and Oller, 1995; Köppe 1996; Deuchar and Quay, 2000; Nicoladis and Secco, 2000) has suggested that bilingual children often have a word for a particular concept in one language but may lack a translation equivalent in the other. This led Lindholm and Padilla (1978) to formulate the LEXICAL GAP HYPOTHESIS which maintains that bilingual children switch from one language to another when they have a lexical gap (i.e. no word for a particular concept in one language, but a word for the concept in the other language): more specifically, they suggested (1978, p. 332) that ' $[\mathrm{c}]$ hildren mix when they do not know the corresponding word in the other language'. A related DOMINANCE HYPOTHESIS was put forward by Petersen (1988) who maintained that bilingual children tend to switch into their dominant/stronger language when using their weaker language because many of the words/structures they need are lacking in the weaker language. Thus, a bilingual boy producing an English sentence like I want the ... might switch to the French noun gâteau "cake" at the end of the sentence if he has not yet acquired the English word cake (or even if he has acquired cake but has a weak memory trace for the word and so fails to retrieve it). And indeed, numerous studies have reported two- and three-year-old bilingual children producing structures like those in (1) above and (13) below containing an ungendered English determiner modifying a gendered $(\mathrm{M}=$ masculine, $\mathrm{F}=$ Feminine, $\mathrm{C}=$ Common $)$ noun:

(13) a. the vaca "cow", the agua $_{F}$ "water", a perro ${ }_{M}$ "dog" (Spanish: Lindholm and Padilla, 1978)

b. a bain "bath", a bateau $_{\mathrm{M}}$ "boat", a main $_{\mathrm{F}}$ "hand", the chaussure "shoe"

(French: Galasso, 2003)

c. the dukke "doll", a bog $_{\mathrm{C}}$ "book", a flaske "bottle"

(Danish: Petersen, 1988)

Such structures might lead us to conclude that young children simply do not obey constraints on mixing, including the gender-based constraints in (12) above. And yet, this would go against evidence from existing research that even children as young as two years of age do indeed obey constraints on mixing: for example, Genesee (2002) claims that the mixed utterances produced by a group of 10 two-year-old English/French bilinguals that he studied conformed to the Free Morpheme Constraint and the Equivalence Constraint of Poplack (1980): see also Paradis, Nicoladis and Genesee (2000). If children do indeed obey constraints on mixing, why should it be that in structures like (13) they seemingly violate the gender-based constraints in (12)? The answer we shall suggest here can be formulated in terms of the following research hypothesis:

\section{(14) Accommodation Hypothesis}

When mixing between a modifier and a noun from different types of languages, bilingual children accommodate the morphological properties of the noun to those of its modifier. 
The concept of ACCOMMODATION is adapted from work by social psychologists on how speakers accommodate their accents to those of their interlocutors (see e.g. Giles, 1973; Giles, Taylor and Bourhis, 1973; Giles and Smith, 1979; Bell, 1984; Coupland, 1984; and Trudgill, 1986). The idea of language-mixing involving some form of accommodation is implicit in the suggestion by MacSwan (2005, pp. 11f.) that word-internal switching is only possible whenever the mixed component is integrated phonologically into the host language (i.e. where there is PHONOLOGICAL accommodation).

Consider first what kind of morphological accommodation would be necessary in order for children to avoid violating the constraint (12i) which blocks mixing between an ungendered determiner and a gendered noun. It might seem as if one way of avoiding violation of this constraint (and the attendant gender-mismatch) in a structure like (4) A GOOD MACCHINA the ungendered determiner $a$ an HONORARY gender feature (i.e. one which it lacks in English): however, this would cause the derivation to crash at the PF interface, since English has no spellout for gender features on determiners (or indeed on other items). An alternative possibility would be to accommodate the Italian noun macchina $_{\text {car }}$ to English noun morphology by STRIPPING it of its gender feature, and treating it as ungendered (when used in an English nominal structure): this would avoid any crash at either interface and result in a convergent structure.

Now consider how a bilingual child might be expected to accommodate the different gender properties of nouns and modifiers in a structure like (7) $\mathrm{UN}_{\mathrm{a}}$ BUONO good CAR containing gendered Italian modifiers and an ungendered English noun. In such a case, it would not be possible to accommodate the different gender properties of the two languages by stripping the Italian modifiers of their gender feature, because Italian has no spellout for ungendered determiners or adjectives. It would therefore seem that the only way of avoiding a gender-mismatch is for the English noun car to be assigned an honorary gender feature (perhaps the feminine gender feature of its Italian counterpart macchina $a_{\text {car }}$ ): this would then ensure convergence at both interface levels.

Finally, consider how a bilingual child might accommodate the French two-gender system and the German three-gender system in a structure like (10) UN GRAND big $_{\mathrm{a}}$

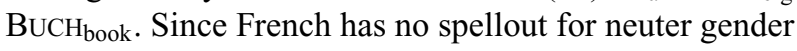
on determiners or adjectives (or indeed on other items), the only way of avoiding a gender-mismatch in such cases is seemingly to assign the neuter noun Buch book one of the two other genders found in French - perhaps masculine (either because its French counterpart livre book is masculine, or because masculine is the default gender in French): this would then ensure convergence. More generally, we might expect German neuter nouns denoting human beings or animals to be assigned masculine or feminine gender on the basis of their sex (e.g. the German neuter noun Mädchen "girl" might be expected to be treated as feminine on the basis of sex), and nouns with translation equivalents to be assigned the gender of their translation counterpart via some form of translexical feature TRANSFER (i.e. transferring a feature from a lexical item in one language to its counterpart in another), and other nouns to be assigned masculine gender by default.

The overall conclusion which our discussion here leads us to is that communicative needs (e.g. caused by a lexical gap or retrieval problem) would be expected to lead bilingual children to obviate violation of gender-based constraints on mixing by accommodating the gender properties of a noun to those of its modifiers when switching between items in languages with different gender systems. An interesting theoretical question which arises from this hypothesis is why a bilingual child should accommodate (e.g.) the gender properties of the noun to those of a modifying determiner. Minimalism offers a principled answer to this question if we suppose that determiners are phase heads (as suggested by the remark in Chomsky, forthcoming, p. 9 that "[s]imilarities between CP and DP suggest that DP too may be a phase, possibilities explored by Svenonius 2004 and Hiraiwa 2005"). Since Chomsky (forthcoming) argues that the head of a phase is responsible (via a form of selection) for "handing over" functional features to subordinate items within the phase, it follows that if the head D of DP is ungendered, the noun it modifies must also be ungendered, and conversely if the head D of DP is gendered, so too must the modified noun be. There are also potential parallels here with claims made in the Matrix Language Frame (=MLF) model of MyersScotton (1993, 2001, 2002), Myers-Scotton and Jake (2001), Jake et al. (2002), which hypothesises that a mixed utterance comprises a morphosyntactic frame from a MATRIX LANGUAGE with morphemes from an EMBEDDED LANGUAGE inserted into this frame, and that properties of the matrix frame determine the nature of the embedded morphemes which can be inserted within it. The potential parallels between MLF and Minimalism become even more striking if we equate the MLF notion of FRAME with the Minimalist notion of PHASE.

In this paper, we aim to test the Accommodation Hypothesis (14) in relation to data from naturalistic corpora exemplifying mixed Concord structures produced by five children who are simultaneous bilinguals. One of these corpora (henceforth referred to as the LUCY CORPUS) comprises naturalistic samples of the free speech of an English-Italian bilingual girl called Lucy collected by Gabriele Azzaro. The corpus comprises weekly recordings (one hour in length) of Lucy's spontaneous speech in conversation with her father (whose native language is Italian, but who lived in England for many years and is fluent in English) and mother (whose native 
language is English but who lived in Italy for many years and is fluent in Italian) between ages 2;3 and 3;4: the recordings were made in a family environment, generally at meal times in the family home near Pistoia in Italy. Both parents used mainly English with Lucy, though other people (e.g. friends and grandparents) spoke to her in Italian. The earlier recordings (from 2;3 to 2;9) are predominantly English, while the later recordings (from $2 ; 10$ to $3 ; 4$ ) are predominantly Italian. Lucy showed high gender accuracy (and Gender Concord) rates throughout the period of the recordings: for example, she showed $94 \%$ correct marking of Number and Gender Concord between an Italian determiner and an Italian noun (in 386/410 tokens). The Lucy data have never previously been reported.

The four other corpora reported on here comprise naturalistic data from French-German bilingual children. One of these comprises naturalistic samples of the language production of a girl called Céline. The relevant data (collected in a research project on early bilingualism directed by Natascha Müller and quantified in Kupisch 2001, 2004 and Kupisch et al. 2002 for DPs and gender concord) covers Céline's development from 2;0.9 to 3;4.9 in German (27 recordings) and from 2;0.9 to $3 ; 6.12$ in French (31 recordings). Céline grew up in Germany, and had a German mother and a French father who each spoke in their native language to her. She was recorded fortnightly until five years of age, in separate language contexts for half an hour per language in natural play situations by native speakers of French and German. The data were collected separately for each language. Céline had a gender accuracy rate of $87 \%$ between $2 ; 0$ and 3;6. The other three corpora (relating to children called Ivar, Annika and Pascal) were collected as part of Jürgen M. Meisel's DUFDE project; see Köppe (1994) for details. All three children lived in Germany, and had French mothers and German fathers who each spoke in their native language to the child. The children were recorded fortnightly until around six years of age, in separate language contexts for half an hour per language in natural play situations, and the interviewers were French and German students. The mixed data reported on here cover the period from $1 ; 10.12$ to $5 ; 01.22$ for Ivar, $1 ; 06.06$ to $4 ; 02.26$ for Annika and 1;05 to $2 ; 11.11$ for Pascal, and have previously been analysed in Köppe (1990, 1997) and Köppe and Meisel (1995); Müller (1994) has analyzed Ivar's data with respect to gender marking in monolingual DPs.

\section{Mixing between an ungendered English modifier and a gendered Italian noun}

In (12i), we saw that convergence requirements bar mixing between an ungendered determiner and a gendered noun. However, we also saw in (13) above that a number of existing studies have reported bilingual children producing such structures. In order to see whether similar structures were attested in our corpus, we looked at relevant data from the English-Italian bilingual child in our study (Lucy). We found that (in the overall corpus), she produced 1,719 tokens of DETERMINER+(ADJECTIVE+) NOUN structures containing an English determiner (if we exclude indeterminate and formulaic expressions, and if we take quantifiers to be a subclass of determiners). 1670 of these structures (97\%) contained an English noun, and 49 (3\%) an Italian noun (excluding from this count bilingual nouns like pasta, foreign borrowings like French bonbon, proper names like Mowgli and onomatopoeic words like choo-choo). Examples of the relevant type of Determiner-Noun mixes produced by Lucy (but not by either of her parents) in the transcripts are given below (with the relevant items in bold, and the gender of the relevant nouns in adult Italian indicated by subscripts):

\section{(15) a. You want a bagno ${ }_{\mathrm{M}}$ ? ("bath" 2;6)

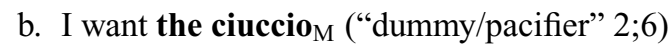

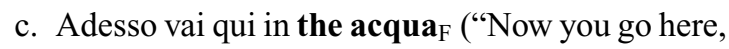 in the water" $2 ; 7$ ) \\ d. I want to go to the muccas $_{\mathrm{F}}$ ("cows" $2 ; 8$ ) \\ e. Yeah, you have a gelato $_{M}$ ("ice-cream" 2;9)

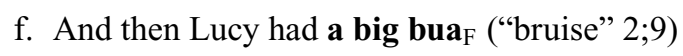

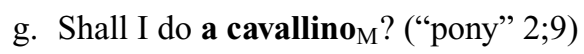 \\ h. I had all your schiacciatina $a_{F}$ ("focaccia bread" $3 ; 0)$}

As these examples illustrate, genderless English determiners are combined with both masculine and feminine Italian nouns. In all 19 mixed structures containing an English determiner unambiguously marked for number (i.e. excluding 30 structures containing determiners like the which show no overt number marking), the modified Italian noun carries a matching number feature - suggesting that Number Concord operates between English determiners and Italian nouns in Lucy's mixed nominals.

Given the constraint (12i) that convergence requirements bar switching between an ungendered determiner and a gendered noun, the obvious question posed by sentences like (15) is why D-N mixing should occur in the child nominals which are marked there in bold. If an Italian noun like gelato "ice-cream" enters the derivation carrying an uninterpretable masculine-gender feature in a sentence like (15e), the nominal $a_{\text {gelato }}$ ice-cream will have the structure (16) below:
(16) $[\mathrm{D}$ a] [N gelato]
[Sg-Num] [u-Num]
[3-Pers] [M-Gen] 
We would then expect the derivation to crash at the semantics interface because the uninterpretable gender feature on the noun cannot be deleted as the determiner has no matching gender feature.

One way of circumventing this problem is to suppose that (in such structures) Lucy accommodates the Italian noun to its English modifier in respect of its Concord features. In other words, Lucy treats Italian nouns modified by an English determiner as carrying the same Concord features as English nouns. In more concrete terms, this would mean that although a noun like gelat $_{\text {ice-cream }}$ carries both number and gender features when modified by an Italian determiner, it carries only number (and not gender) when modified by an English determiner and used as an honorary English noun. On this view, a mixed nominal like a gelato would comprise an ungendered determiner modifying an ungendered noun, as in (17) below:

\section{(17) $[\mathrm{D}$ a] [N gelato] \\ [Sg-Num] [u-Num] \\ [3-Pers]}

and the resulting derivation would ultimately be convergent. In the case of a mixed DP like the muccas "the cows" in (15d), the noun mucca $_{\text {cow }}$ seems to be treated as a NONCE BORROWING (i.e. non-established borrowing) and hence carries the English plural $-s$ suffix. ${ }^{4}$ Such an analysis would also predict that an Italian noun modified by an English determiner would be treated as genderless, and hence would not be modified by a gendered Italian adjective: and in this connection, it is interesting to note that none of the 11 structures of the form ENGLISH DETERMINER + ADJECTIVE+ITALIAN NOUN produced by Lucy contained an Italian adjective (all the adjectives occurring in such structures being ungendered English adjectives).

To summarise: Lucy produces a number of mixed nominals of the form ENGLISH DETERMINER+ITALIAN NOUN which at first sight seem to violate the constraint (12i) that convergence considerations bar mixing between an ungendered determiner and a gendered noun. However, we have argued that the morphology of the Italian nouns in such structures is accommodated to that of their English counterparts. In other words, they are treated as honorary English nouns, so that (like other nouns in English) they do not carry grammatical gender. If so, the relevant nominals are convergent at both interfaces, and so are consistent with our convergence/accommodation account of mixing.

\footnotetext{
4 There is extensive discussion in the relevant literature of the idea that bilinguals "borrow" nouns from one language into another (See Pfaff, 1979; Poplack, 1980; Sankoff and Poplack, 1981; Nartey, 1982; Poplack, Wheeler and Westwood, 1989; Sankoff, Poplack and Vanniarajan, 1990; Muysken, 1995; Poplack and Meechan, 1995; Halmari, 1997; Boumans, 2001).
}

\section{Mixing between a gendered Italian modifier and an ungendered English noun}

In (12ii), we noted that convergence requirements block mixing in adult nominals which comprise a gendered modifier and an ungendered noun, and that Belazi et al. (1994) report that such mixes are not found in adult Spanish-English bilinguals. However, the same constraint seems at first sight not to hold for bilingual children: for example, Lindholm and Padilla (1978, p. 331) report that Spanish-English bilingual children in their study (aged from 2;10 to 6;2) produced a range of structures involving an ungendered English noun with a gendered Spanish modifier, including nominals such as $l a_{\mathrm{F} . S g} l a d y$ "the lady", $u n_{\mathrm{M} . S g}$ boy "a boy", and este M.Sg $_{\text {bird "this }}$ bird"; likewise, Cornejo (1975) reports English-Spanish bilingual children producing similar mixed structures such as $l a_{\mathrm{F} . S g}$ bottle "the bottle". In the light of these findings, we searched our English-Italian Lucy corpus to see whether there were examples of such mixed nominals.

In the relevant corpus, there were 630 tokens of nominal structures comprising an Italian determiner and/or adjective modifying a noun. 600 of these structures (95\%) contained an Italian noun, and $30(5 \%)$ an English noun. Examples of structures where Lucy switches from an Italian modifier to an English noun are given below:

(18) a. Questo ${ }_{\text {M.Sg }}$ è un $_{\text {M.Sg }}$ gooso $(2 ; 8)$ "This is a goose"

b. È $\quad \mathbf{i l}_{\text {M.Sg }}$ lion $(2 ; 9)$ "It's the lion"

c. con $\quad \mathbf{a}_{\mathrm{F} . S g}$ butterfly $(2 ; 10)$

"with the butterfly"

d. Come questa ${ }_{F . S g}$ butterflaia "like this butterfly"

e. Dov'è la $\mathbf{a}_{\mathrm{F} . S g}$ spoona? $(2 ; 11)$ "Where's the spoon?"

In eight cases (gooso "goose", ducko "duck", bono "bone", butterflaia "butterfly", spoona "spoon", balloona "balloon", creama "cream", froghella "froggy") the resulting noun was a hybrid form comprising an English stem with an Italian number/gender affix added to it (either the masculine singular affix - $o$ or the feminine singular affix $-a$ ), and in one of these cases (froghella "froggy") the noun carried the Italian diminutive derivational infix -ell- as well. In a further seven cases (butterfly, cockerel, coffee, kangaroo, lion, plate, story), an English noun was used in an unmodified form. On the face of it, structures like (18) appear to violate the constraint (12ii) which bars mixing between a gendered modifier and an ungendered noun. So what is going on in such structures? 
The answer suggested by the Accommodation Hypothesis (14) is that when an English noun is inserted into an Italian DP, its morphological features are accommodated to the requirements of Italian DPs: consequently, the noun is treated as an honorary Italian noun and assigned (masculine or feminine) gender. In the case of hybrid nouns like gooso "goose" (comprising the English stem goose and the Italian masculine singular affix -o) and spoona "spoon" (comprising the English stem spoon and the Italian feminine singular affix $-a$ ), this gender accommodation is achieved by adding an Italian number/gender affix to an English stem, thereby assigning the noun a gender feature which it lacks in English, with the result that (by virtue of the gender carried by the affix) the noun can value the unvalued gender feature on modifying Italian determiners or adjectives. On this view, attaching a gendered Italian affix to a genderless English noun stem is an accommodation strategy designed to ensure convergence, and results in the noun being treated as a NONCE BORROWING. What lends empirical support to this suggestion is the fact that Lucy always uses the correctly gendered form of the definite/indefinite article with the relevant noun - producing e.g. three tokens of un gooso "a goose" in which the masculine singular indefinite article un "a" modifies the masculine singular noun gooso "goose" and four tokens of la spoona "the spoon" in which the feminine singular definite article la "the" modifies the feminine singular noun spoona "spoon".

Still, this leaves the question of why Lucy should attach the Italian masculine affix - $o$ to some hybrid nouns (gooso, ducko, bono), and the feminine affix - $a$ to others (creama, butterflaia, spoona, balloona, froghella). In the case of the masculine hybrid bono and the feminine hybrids creama, butterflaia and froghella, this could be the result of gender transfer from their Italian counterparts (the masculine noun osso "bone", and the feminine nouns crema "cream", farfalla "butterfly" and rana "frog"). If we follow MacSwan (2005) in supposing that bilinguals have two distinct lexicons, this TRANSFER story would mean that a noun is assigned the gender specified in the lexical entry of its counterpart in the other language: and this in turn presupposes a complex TRANSLEXICAL mechanism by which a bilingual child accesses related lexical entries from two separate lexicons. The attendant complexities of such a translexical story could be avoided if bilinguals have a single lexicon and if translation counterparts (like butterfly/farfalla) have a single lexical entry (characterised e.g. by a common set of semantic features) with multiple spellouts (one in English and another in Italian) - thereby also maximising lexical economy (in that under the TWO-LEXICONS model, there would be a considerable duplication of information in the entries for butterfly and farfalla). For concreteness, let us suppose that the noun butterfly/farfalla has a common lexical entry along the lines shown in schematic form below:

\begin{tabular}{lllc}
\hline \hline BUTTERFLY/ & & & \\
FARFALLA & Stem & Features & Affix \\
\hline Italian & farfall- & u-Num, F-Gen & $-a$ \\
English & butterfly & u-Num & $-\varnothing$ \\
\hline \hline
\end{tabular}

The table in (19) tells us that the relevant item has the stem farfall- in Italian and butterfly- in English, that it enters the syntax with unvalued number features in both English and Italian, and an additional feminine gender feature in Italian, and that the inflectional affix associated with it is $-a$ (plural $-e$ ) in Italian and $-\varnothing$ (plural $-s$ ) in English. When Lucy says questa ${ }_{\mathrm{F} . S g}$ butterflaia "this butterfly" in (18d), she is assigning the noun the grammatical (number and gender) features which it has in Italian, the affix which it has in Italian, but the stem spellout which it has in English. Note that an implicit assumption which is being made here is that a bilingual child may have problems in retrieving part of the lexical entry for a given item (in this case, the Italian spellout for the stem).

However, we could not tell the same gender transfer story about the masculine hybrids gooso/ducko (which have the feminine Italian counterparts ocalanatra) nor about the feminine hybrids spoona/balloona (which have the masculine counterparts cucchiaio/pallone). It may perhaps be that the nouns gooso/ducko are assigned a masculine gender affix by virtue of the assumed male sex of their referents: ${ }^{5}$ in other words, Lucy may have developed redundancy rules to the effect that nouns denoting male beings are typically masculine in gender, and that the most frequent type of regular masculine nouns have a singular form ending in - $o$. And in the case of the feminine hybrids spoona/balloona, it may be that a near rhyme with the stem of feminine forms like una "a" and luna "moon" is a factor (so that phonological form may play a role in gender assignment).

However, in addition to hybrid nouns of the form ENGLish STEM + ITALIAN AFFIX, Lucy also uses seven English nouns in unmodified form in mixed nominals (butterfly, cockerel, coffee, kangaroo, lion, plate, story). Six of the mixed nouns are assigned the same gender as their Italian counterparts, with Lucy treating cockerel/coffee/kangaroo/plate as masculine for concord purposes (like their Italian counterparts galletto/caffè/kanguro/piatto), and butterfly/story as feminine (like their Italian counterparts farfalla/storia):

\footnotetext{
5 An alternative possibility (which we will not discuss further here) is that either or both of the nouns may be assigned masculine gender by default.
} 
it would seem that she again utilises a transfer strategy parallel to that outlined above to assign such nouns gender. Thus, when Lucy says $l a_{\mathrm{F} . S g}$ butterfly in (18c), she is assigning the noun the grammatical features which it has in Italian (including its feminine gender feature), but is giving both the stem and the affix an English spellout; see (19) above.

What remains to be accounted for is Lucy's treatment of the noun lion, which is used in unmodified form in mixed nominals - as in the phrase $i l_{\mathrm{M} . S g}$ lion "the lion" in (19b). The word lion is is treated as masculine in gender (like its Italian counterpart leone) in three mixed concord structures (e.g. $i l_{\mathrm{M} . S g}$ lion "the lion") and feminine in three others (e.g. la $a_{\text {F.Sg }}$ lion "the lion"): since the three feminine uses of lion all occur in the same transcript, it may be that Lucy assigns the noun feminine gender on the basis of the assumed sex of its referent if it denotes a specific animal (e.g. in a picture book or TV programme) taken by Lucy to be a lioness: however, since we lack the relevant contextual information, this remains conjecture. What lends some plausibility to this story is the fact that the (very few) concord errors made by Lucy typically involve animal names: for example, there are 18 tokens of the noun gatto "cat" being correctly treated as masculine in gender, and two of it being treated as feminine; when it is used as feminine (to denote a female cat like her pet cat Flora), it would seem that Lucy allows semantic gender to over-ride morpho-phonological gender.

To summarise: Lucy produces a range of mixed nominals in which a gendered Italian modifier is used with an English noun: in such cases convergence is ensured by accommodating the feature composition of the English noun to that of its gendered modifiers by assigning the noun a gender on the basis of transfer, form (i.e. rhyme) or sex. Assigning gender to English nouns in mixed nominals is an accommodation strategy designed to ensure convergence, and thus serves to minimise crashes, maximise computational efficiency, and avoid any potential breakdown in communication.

Having looked at mixing between a gendered and an ungendered language, we now turn to look at mixing between languages like French and German with asymmetric gender systems (French having two genders and German three). In section 7 we look at mixing between German modifiers and French nouns, while in section 8 we examine mixing between French modifiers and German nouns.

\section{Asymmetric mixing between German (three-gendered) modifiers and French (two-gendered) nouns}

In (12iii), we hypothesised that mixing between a gendered modifier and a gendered noun should be permissible unless the noun has a language-specific gender value (i.e. one which is not found in the language of the modifier). We should therefore expect mixing to be possible between a German modifier and a French noun, since French nouns are masculine or feminine in gender, and German modifiers can also be masculine or feminine (as well as neuter). In this section, we see whether this prediction holds for the four French-German bilingual children included in our study.

Céline produces the following structures containing a gender-transparent German determiner and a gendered French noun:

(20) a. eine fessée $_{F}$ (“a spanking” 2;9), (ei)ne f $_{\mathrm{F}}$ tortue $_{\mathrm{F}}$ ("a turtle" $3 ; 6$ ), ein $_{M}$ dodo $_{M}$ ("a boat" $2 ; 1$ )

b. ein $_{\mathrm{M} / \mathrm{N}} \operatorname{montan}_{\mathrm{F}}$ ("a mountain" $2 ; 3$ )

c. $\operatorname{die}_{\mathrm{F}} \operatorname{große}_{\mathrm{F}}$ cheval $_{\mathrm{M}}$ ("the big horse" $2 ; 0$ ), die $_{\mathrm{F}}$ train $_{M}$ ("the train" $2 ; 5$ )

In (20a), we find the expected match in gender between a German determiner and a masculine or feminine French noun which it modifies. In (20b), there is a seeming gender mismatch between the masculine/neuter German determiner ein "a" and the feminine French noun montagne "mountain": what may well be happening here is that (via transfer) the gender of montagne "mountain" is accommodated to the masculine gender of its German counterpart Berg "mountain", and accordingly the noun triggers masculine concord in the article. (Interestingly, the noun also appears to be accommodated to German phonology by replacing the palatal nasal consonant at the end of the French word by an alveolar nasal.) Two further cases of apparent gender-mismatch are found in (20c), where we have feminine German articles with a masculine French noun. The case of $\operatorname{die}_{\mathrm{F}} \operatorname{gro}_{3} e_{\mathrm{F}}$ cheval $_{\mathrm{M}}$ "the big horse" may be parallel to Lucy's use of feminine concord with the masculine Italian noun gatto "cat": in other words, the noun may be assigned feminine gender on the basis of the assumed female sex of the horse in question. As for die $e_{\mathrm{F}} \operatorname{train}_{\mathrm{M}}$ "the train", it could be that train is treated as feminine via transfer from its feminine German counterpart Lokomotive "train": if so, Céline correctly matches the gender of the determiner to that of the (assumed) feminine gender of the noun. If the analyses proposed here are along the right lines, the structures in (20) show German modifiers being assigned a gender which matches the hypothesised gender of the French noun, and so are convergent.

Ivar acquires gender contrasts in German determiners around age 2;4 (see Koehn 1994, p. 40). If we look at his gender-transparent modifier-noun mixes after this point (listed below), we find that (as expected) he generally shows correct Gender Concord with both masculine and 
feminine nouns - with the one exception in (21c):

(21) a. $\operatorname{ein}_{M}$ conducteur ${ }_{M}$ ("a driver" 2;8), $\operatorname{ein}_{M}$ couteau $_{M}$ ("a knife" $2 ; 8$ ), mein $_{M}$ balai $_{M}$ ("my broom" 3;0), ein ${ }_{M}$ livre $_{M}$ (“a book" 3;2), ein ${ }_{M}$ böser $_{M}$ zom $_{M}^{6}$ ("an evil man" 3;3), ein oma-masque $_{\mathrm{M}}$ ("a grandmother-mask" 4;11)

b. $\operatorname{die}_{\mathrm{F}}$ ceinture $_{\mathrm{F}}$ ("the belt" $2 ; 8$ ), eine $\mathrm{F}_{\mathrm{F}}$ tortue $\mathrm{F}_{\mathrm{F}}$ ("a turtle" $3 ; 1$ ), eine mouche $_{\mathrm{F}}$ ("a fly" $3 ; 2$ ), die $\mathrm{F}_{\mathrm{F}}$ mer $_{\mathrm{F}}$ ("the sea" $3 ; 8$ )

c. ein $_{\mathrm{M} / \mathrm{N}}$ lalune $_{\mathrm{F}}$ ("a the.moon" $3 ; 2$ )

(21c) appears to involve a segmentation error, with the French feminine singular definite article la "the" misanalysed as part of the stem of the noun lune "moon". Of more direct concern to us here is the question of why there should be an unexpected mismatch between the feminine gender of the French noun and the masculine gender of the German determiner. A plausible answer is that this is the result of gender transfer: in other words, Ivar assigns to the French noun (la)lune the masculine gender of its German counterpart Mond. If so, and if the article ein "a" is also masculine, all the structures in (21) are convergent.

Annika acquires gender contrasts (in modifiers such as ein/eine "a" and mein/meine "my") at around 2;3. She produces five tokens of structures (listed below) containing a gender-transparent German modifier with a French noun, only two of which potentially show gender convergence:

(22) a. $\operatorname{ein}_{M} \operatorname{pot}_{M}$ (“a pot" 2;8)

b. eine $_{\mathrm{F}}$ madame $_{\mathrm{F}}$ (“a lady” $2 ; 8$ )

c. mein $_{\mathrm{M} / \mathrm{N}}$ poule $_{\mathrm{F}}$ ("my chicken" $2 ; 3$, occurring twice), $^{\text {ein }}$ M/N $_{\mathrm{N}}$ ceinture ("a belt" $2 ; 8$ )

Why should Annika use a masculine/neuter German determiner to modify a feminine French noun in structures like (22c)? In the case of mein poule "my chicken", it may be that confusion between the feminine French noun poule "hen" and its masculine counterpart poulet "chicken" causes poule to be treated as a masculine noun and thus to be modified by a (potentially) masculine modifier like mein "my". In the case of ein $\mathrm{M} / \mathrm{N}$ ceinture $_{\mathrm{F}}$ "a belt", it may well be that Annika assigns the French noun masculine gender via transfer, on the basis that its German counterpart Gürtel "belt" is masculine. If so, the structures in (22) will be convergent.

Pascal shows productive use of gender contrasts (in modifiers like ein/eine "a", mein/meine "my", and der/die/das "the") from age 2;2. The only three structures he produced containing a gender-transparent German

\footnotetext{
6 [zom] presumably arises via mis-segmentation of plural forms like les hommes "the men", where the final segment of les is pronounced [z] before a word beginning with a vowel.
}

modifier and a French noun are listed below:
(23) a. $\operatorname{ein}_{M} \operatorname{avion}_{M}$ (“a plane” 2;2), ein ${ }_{M}$ bobo $_{M}$ ("a bruise" 2;7)

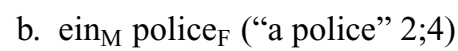

The two structures in (23a) are convergent - though not that in (23b). If Pascal is using the word police (in a nonnative fashion) to refer to an individual male policeman, it may be that he assigns the noun masculine gender on the basis of the sex of its referent.

The overall conclusion to be drawn from this section is that most of the structures produced by the four children which contain a German modifier and a French noun are convergent: structures where there appears (at first sight) to be a gender mismatch can plausibly be handled by supposing that the relevant French noun is assigned a non-native gender (e.g. via a transfer-based or sex-based strategy), with the modifier then being assigned the same gender as the assumed gender of the noun. If so, then all the relevant structures will be convergent.

\section{Asymmetric mixing between French (two-gendered) modifiers and German (three-gendered) nouns}

A further constraint on mixing noted in (12iii) is that mixing is possible between French modifiers and German masculine or feminine nouns, but not between French modifiers and German neuter nouns (because French has no spellout for neuter gender). However, as noted in section 4, the Accommodation Hypothesis would lead us to expect children to obviate this constraint by treating German neuter nouns as masculine or feminine in gender when modified by a French determiner (with the noun typically being assigned masculine gender by default, though sometimes being assigned feminine gender when denoting a female entity or when its French counterpart is feminine). In this section, we turn to test this prediction in relation to the four French-German bilingual children in our study.

Consider first the prediction that the children (once they have acquired gender) will use a gender-matched French modifier with a German masculine or feminine noun. Céline produced 21 structures containing a gendertransparent French modifier and a German masculine or feminine noun. 13 of these were structures like (24a) below in which both modifier and noun are masculine; four were structures like (24b) in which both modifier and noun carry the same gender; and four were structures like (24c) showing an apparent gender mismatch:

(24) a. un Bär ${ }_{M}$ ("a bear" 2;5), un ${ }_{M}$ Wolf $_{M}$ ("a wolf” 2;6), le $_{M}$ Junge $_{M}$ ("the boy" 2;7), un Usel $_{M}$ ("a

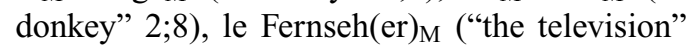
$2 ; 10$ ), un Löffel $_{\mathrm{M}}$ (“a spoon” 2;11), le $\mathrm{e}_{\mathrm{M}}$ 
Fliegenpilz $\mathrm{M}_{\mathrm{M}}$ ("the fly agaric" 3;6), $\mathrm{le}_{\mathrm{M}}$ Eiswürfel $_{\mathrm{M}}$ ("the ice-cube" 4;0)

b. une Schlange $_{\mathrm{F}}$ ("a snake" 2;3), une Lampe $_{\mathrm{F}}$ ("a lamp" 3;0), une F $_{\mathrm{F}}$ Angel $_{\mathrm{F}}$ ("a fishing rod" 3;5), une $_{\mathrm{F}}$ Biene $_{\mathrm{F}}$ ("a bee" 3;6)

c. une $\mathrm{F}_{\mathrm{F}}$ Sattel $_{\mathrm{M}}$ ("a saddle" 2;3), $\mathrm{le}_{\mathrm{M}} \mathrm{Uhr}_{\mathrm{F}}$ ("the clock" $2 ; 10), \mathrm{le}_{\mathrm{M}} \mathrm{Kann}_{\mathrm{F}}$ (=Kanne) "the pot" $(2 ; 11)$, ma $_{\mathrm{F}}$ Bruder $_{\mathrm{M}}$ ("my brother" $\left.2 ; 11\right)$

On the face of it, $17 / 21(81 \%)$ of the structures show the predicted gender convergence, and 4/21 (19\%) show an unexpected gender mismatch. However, the apparent cases of mismatch may not be what they seem. After all, Céline may use a phonological gender assignment condition to assign masculine gender to the noun $U h r$ in (24c), on the basis that monosyllabic nouns in German are typically masculine: see Müller $(1994$, p. 72$)$ for evidence that children treat monosyllabic German nouns as masculine - e.g. feminine nouns such as Tür "door" and neuter nouns such as Dach "roof": if so, the structure will be convergent. Moreover, in the case of une Sattel "a saddle", it may well be that the noun Sattel "saddle" is assigned feminine gender via transfer from its feminine French counterpart selle - in which case, the structure is once again convergent. The same holds for the DP le Kann "the pot" with the French counterpart le pot though a phonological explanation, as with le Uhr, might alternatively be envisaged here. More puzzling is $m a$ Bruder "my brother"; it could be that (as with the English his/her contrast and the parallel German sein/ihr contrast) the gender of $m a$ reflects the (female) sex of the possessor rather than the gender of the possessum. If so, none of the structures in (24) pose any serious empirical challenge to the convergence account of mixing.

Ivar acquires gender in French articles at around age 2;4 (Koehn 1994, p. 40). He subsequently produces 16 structures containing a gender-transparent French modifier and a German masculine/feminine noun, 14 of which are gender-convergent (7 containing a masculine noun as in $l e_{\mathrm{M}} \operatorname{Korb}_{\mathrm{M}}$ "the basket" 2;11;un petit $_{\mathrm{M}}$ Fotoapparat $_{\mathrm{M}}$ "a little camera" 3;0; le $e_{\mathrm{M}} \operatorname{Kopf}_{\mathrm{M}}$ "the head" $3 ; 1$, and seven containing a feminine noun as in $l a_{\mathrm{F}}$ Spielgruppe $_{\mathrm{F}}$ "the playgroup" 3;3), and one of which $\left(\right.$ un $_{\mathrm{M}}$ Pflaster $_{\mathrm{N}}$ "a plaster" $2 ; 11$ ) contains a neuter noun which is used with a masculine article and so is seemingly assigned masculine gender by default. Only one of the 16 mixed nominals of this type contains a seeming gender-mismatch. Since the context in which it occurs is instructive, the relevant portion of the transcript (from a recording made when Ivar was 3;5) is given in full below (where $\mathrm{F}$ denotes the interviewer):

(25) Ivar: (Das) is $\mathrm{la}_{\mathrm{F}}$ Nachtigall $_{\mathrm{F}}$ "(That) is the nightingale"
F: Ça c'est pas - ça c'est un
"It isn't - it's a rossignol" (="nighol
Mingale")

Ivar: Ça c' - Das ist eine $\mathrm{F}_{\mathrm{F}} \mathrm{Nachtigall}_{\mathrm{F}}$ "It - It's a nightingale"

F: Mais non, ça c'est un rossignol $_{M}$ "No, it's a rossignol"

Ivar: $\mathrm{Un}_{\mathrm{M}} \mathrm{Nachtigall}_{\mathrm{F}}, \mathrm{un}_{\mathrm{M}} \mathrm{Nachtigall}_{\mathrm{F}}$ "A nightingale, a nightingale"

Ivar starts out by (correctly) using the French feminine article la "the" and the German feminine article eine "a" to modify the German feminine noun Nachtigall "nightingale". But when the interviewer twice replaces the German feminine Nachtigall by its French masculine counterpart rossignol, Ivar then proceeds to use the French masculine article un "a" to modify the German feminine noun Nachtigall. It seems likely that this is the result of Ivar transferring the masculine gender of rossignol to its German counterpart. If this is indeed what happens, the two nominals in the last line of the transcript extract in (25) are gender-convergent after all.

Annika acquires the gender of French articles at around 2;3. She subsequently produces eight structures containing a French modifier and a German masculine/feminine noun, all gender-convergent: six contain masculine nouns (as in le Ofen "the oven" 3;5), and two feminine nouns (as in une Schaukel "a swing" $3 ; 2$ ). Thus, she behaves as convergence considerations would predict.

Pascal acquires the gender of French articles at around $1 ; 10$. He produces only five mixed structures containing a French modifier and a German masculine/feminine noun, four of which show correct gender matching - three with masculine nouns as in $l e_{\mathrm{M}}$ Bruder $_{\mathrm{M}}$ ("the brother" 2;4), and one with a feminine noun viz. une $e_{\mathrm{F}}$ Pfeife $_{\mathrm{F}}$ ("a pipe" $2 ; 7)$. The only seemingly gender-mismatched structure of the relevant type which she produces is:

\section{(26) $\mathrm{le}_{\mathrm{M}} \mathrm{Oma}_{\mathrm{F}}$ ("the grandmother" 2;2)}

It is not clear what is going on in (26). An interesting point to note is that the French definite article normally has the proclitic form $l$ ' before a word beginning with a vowel, and yet bilingual children appear to be reluctant to cliticise a French article onto a German noun beginning with a vowel - as we see from the fact that Annika produced phrases like le Ofen ("the oven" 3;5) and le Arzt ("the doctor" 3;7) and Céline produced le Uhr "the clock". An intriguing possibility is thus that the vowel schwa is epenthesised to the contracted feminine article $l$ ' in order to prevent proclisis (and indeed nominals in High German do not generally allow proclisis, perhaps because of preglottalisation of initial vowels). 
Let us now turn to see what happens when French modifiers are used with German neuter nouns. Recall that we hypothesised in section 4 that in such structures, the gender of the German noun would be accommodated to that of its French modifiers (e.g. by assigning the noun masculine gender by default). And indeed this prediction appears to be borne out by the fact that all four French-German bilingual children in our study produced structures in which they used a (gender-transparent) MASCULINE French modifier with a neuter German noun (suggesting that the noun is treated as masculine in gender). More specifically, Céline produces eight such structures including those below:

(27) $\operatorname{un}_{M} \operatorname{Kind}_{N}$ ("a child" 2;11), le $e_{M}$ Kopfkissen $_{N}$ ("the pillow" 2;11), le $\mathrm{e}_{\mathrm{M}}$ Paddel $_{\mathrm{N}}$ ("the paddle" 3;4), $\mathrm{du}_{\mathrm{M}}$ $\mathrm{Heu}_{\mathrm{N}}$ ("some hay" 3;5)

Similarly, Annika produces seven such structures, Ivar four, and Pascal one.

Indeed, it would seem as if gender accommodation goes even further, and that the French-German bilingual children in our study treat neuter nouns as masculine even in structures where they are modified by a German determiner (seemingly accommodating the German threegender system to the French two-gender system). For example, Céline uses a masculine determiner to modify a neuter noun in monolingual German nominal structures such as those below: ${ }^{7}$

(28) den Fahrrad ("the bike" 2;3), den Schiff ("the ship" $2 ; 3$ ), den Buch ("the book" 2;4), den Baby "the baby" $(2 ; 6)$, der andre Schiff ("the other ship" $2 ; 6$ ), (der gleiche Bild "the same picture" 2;6), der Mädchen ("the girl" $2 ; 8$ ), der Spiel ("the game" $2 ; 8$ ), der Pferd ("the horse" $2 ; 8$ ), den Zelt ("the tent" $2 ; 10$ ), den Sofa ("the sofa" $2 ; 10$ ), der Krokodil ("the crocodile" 2;10), den Känguruh ("the kangoroo" $2 ; 10$ ), den Bett ("the bed" $2 ; 11$ ), der Auto ("the car" $2 ; 11$ ), der Haus ("the house" $2 ; 11$ ), den Pferd ("the horse" 2;11), der Krankenhaus ("the hospital" 2;11)

A parallel phenomenon is reported for Ivar in Koehn (1994) and Müller (1994). For example, Koehn (1994, p. 47) reports that "Ivar first establishes a two-class system with a masculine and a feminine gender class. Most of the neuter nouns are attributed masculine gender". She points out (p. 48) that one factor in this could be that in German "the neuter and the masculine gender paradigm are partially identical. Another factor could be the child's bilingualism - i.e. the described behaviour could reflect

\footnotetext{
7 She also produced a smaller number of structures in which neuter nouns were treated as feminine.
}

the tendency to transfer the French two-class system to the German language." 8

\section{Summary and conclusion}

We began this paper in section 2 by looking at constraints proposed in earlier work on how universal principles constrain sentence-internal language mixing, noting that a number of studies have proposed a general constraint to the effect that mixing is only possible where mixed constituents are COHERENT, CONSISTENT, CONGRUENT or COHESIVE. We noted that although these terms tend to be used pre-theoretically in much earlier work, it is possible to give them a precise theoretical formulation in terms of the notion of CONVERGENCE within Minimalism. In section 3, we went on to show how operations like Concord ensure convergence at the PF interface by valuing unvalued features and at the semantics interface by deleting uninterpretable features. We then outlined a convergence-based account of mixing under which the primary grammatical constraint on mixing is that it is only possible where it leads to convergence at both interfaces. We hypothesised that the CONVERGENCE account would (on certain reasonable theoretical assumptions) predict that mixing between a modifier and noun would be barred (because it would give rise to a gender mismatch leading to a crash) in three types of structure - viz. (i) between an ungendered determiner and a gendered noun, (ii) between a gendered modifier and an ungendered noun, and (iii) between a gendered modifier and a noun with a language-specific gender value. In section 4, we looked at the development of bilingual children, and formulated an ACCOMMODATION HYPOTHESIS to the effect that in cases where communicative needs (e.g. lexical gaps or retrieval problems) lead them to switch languages in MODIFIER+NOUN structures, they overcome any potential feature-mismatch by accommodating the features of the noun to those of its modifier. We predicted that this

8 It could be objected that (if neuter gender is not acquired until around three years of age - as argued by Koehn, 1994 and Müller, 1994) German has the same two-gender system as French for bilingual children, and hence there is no evidence of any form of gender accommodation in the mixed nominals produced by two-year-olds. However, we could seemingly not account for the use of masculine French determiners with neuter German nouns after this age (e.g. in structures like $u n_{\mathrm{M}}$ Bild $d_{\mathrm{N}}$ "a picture" produced by Annika at $3 ; 11$ ) by supposing that the children treat all German neuter nouns as masculine. An interesting incidental descriptive detail is that Céline seems to assign gender inconsistently to some neuter nouns: for example, the neuter noun Pferd "horse" is modified by a neuter definite article in $d_{a s_{\mathrm{N}}}$ Pferd "the horse", by a masculine in $\operatorname{der}_{\mathrm{M}} /$ den $_{\mathrm{M}}$ Pferd, and by a feminine in $d_{i e}$ Fferd. This may mean that Céline sometimes manages to retrieve the neuter gender of Pferd from its lexical entry, and sometimes does not: when she does not, she may assign the noun masculine/feminine gender on the basis of the assumed sex of the referent. 
would lead bilingual children to (i) strip gendered nouns of their gender when they are modified by ungendered determiners, (ii) assign gender to ungendered nouns when they have gendered modifiers, and (iii) assign nouns with a language-specific gender to another gender class when used with modifiers which cannot spell out the relevant gender. We set out to test our predictions in relation to data from two types of bilingual child corpora (the English-Italian LUCY corpus, and the French-German CÉLINE, IVAR, ANNIKA and PASCAL corpora). In section 5 we saw that Lucy used ungendered English determiners to modify gendered Italian nouns, and we argued that this was because the relevant Italian nouns were stripped of their gender in order to accommodate them to the ungendered determiner modifying them. In section 6 , we saw that Lucy produced numerous structures containing a gendered Italian modifier used with an ungendered English noun: we accounted for this by arguing that the relevant English nouns were accommodated to their modifiers by being treated as honorary Italian nouns, and assigned gender via a transfer-based strategy, a sexbased strategy or a form-based strategy (based on stem rhyme), and we suggested that gender transfer can be accounted for more straightforwardly if bilingual children are assumed to have a single lexicon rather than two separate ones. In section 7, we saw that the FrenchGerman bilingual children in our study generally used gender-matched German determiners to modify French nouns, with apparent cases of gender-mismatch being attributable to French nouns being assigned a non-native gender via a transfer-based or sex-based strategy (and the modifier then being assigned the same gender as the assumed gender of the noun). In section 8 , we found that (as expected) the children generally correctly matched the gender of French modifiers to that of German masculine or feminine nouns (with apparent mismatches again being the result of transfer-based, sex-based or form-based gender assignment conditions). Furthermore, we also found that (as predicted) they accommodated the gender properties of German neuter nouns to those of French modifiers by re-assigning them to one of the two French gender classes (generally to the default masculine gender), so preventing the derivation from crashing.

Our overall conclusion is that (in mixed nominals which would otherwise be expected to give rise to a gender-mismatches and hence cause crashes), communicative needs (caused e.g. by lexical gaps or retrieval problems) lead bilingual children to accommodate the gender properties of a noun to those of its modifiers in order to maximise convergence. The fact that children thereby manage to obviate gendermismatches (and the attendant crashes that this would give rise to at the interface levels) suggests that Chomsky's characterisation of grammars as perfect systems of optimal design applies to bilingual as well as monolingual grammars. $^{9}$

However, an interesting question left unanswered by our work on bilingual children here is the extent to which adults also resort to similar accommodation strategies in order to avoid potential crashes in mixed structures. Results from a number of studies would suggest that this is indeed the case. For example, Carol Pfaff (1979) reports adult Spanish-English bilinguals producing nominals like those below in which a gendered Spanish determiner is used to modify an ungendered English noun:

(29) a. $\mathbf{u n}_{\mathrm{M} . S g}$ boxer "a boxer"

b. $\mathbf{l a}_{\mathrm{F} . S g}$ maid "the maid"

c. la $\mathbf{a}_{\mathrm{F} . S g}$ coast

"the coast"

d. unos $_{\text {M.P1 }}$ traditions "some traditions"

In $(29 a, b)$, the English nouns seem to be assigned honorary masculine gender on the basis of the sex of their referents; in (29c) the noun coast is seemingly assigned honorary feminine gender via transfer, because its Spanish counterpart costa is feminine; and in (29d), the noun traditions appears to be assigned honorary masculine gender by a default condition to the effect that nouns (if not assigned gender via sex or transfer) are assigned masculine gender by default. In much the same vein, Jake et al. (2002) report that adult SpanishEnglish bilinguals allow switching between a Spanish determiner and an English noun. In addition, MacSwan (1997, pp. 252f.) reports Spanish-Nahuatl bilinguals accepting mixing between a gendered Spanish determiner and a genderless Nahuatl noun in nominals such as $u n_{\mathrm{M} . S g}$ konetl "a son", where the noun would seem to be assigned masculine gender on the basis of the sex of its referent. What this suggests is that both adult and child bilinguals make use of accommodation. However, the reasons for language-mixing are likely to be different in the two cases. Whereas for children, mixing may be motivated in large measure by lexical gaps or lexical retrieval problems, this is less likely in the case of adults, where other factors may play a role. For example, switching from French to English in nominals like $l e_{\text {the }}$ boss, $l e_{\text {the }}$ cash, $l e_{\text {the }}$ casting, le $e_{\text {the }}$ fitness, le $e_{\text {the }}$ timing, le $e_{\text {the }}$ travelling, un challenge,

\footnotetext{
9 An interesting issue which we were not able to investigate in this paper (given that our data came from children speaking English, French, German and Italian) and which we set aside for future research is what happens in cases where children acquire two languages with distinct two-gender systems - e.g. Swedish-Italian bilinguals.
} 
$u n_{\mathrm{an}}$ interview, $u n_{\mathrm{a}}$ mail ("an e-mail"), $u n_{\mathrm{a}}$ thriller, is not motivated by the absence of French translation counterparts for the relevant items, but seems rather to stem from cultural factors (e.g. the perceived 'trendiness' of using English terms in certain cultural domains). However, although switching in adult and child grammars may be motivated by different factors, in both cases the morphological properties of the relevant nouns (including their gender properties) must be accommodated to those of their modifiers.

\section{References}

Abney, S. P. (1987). The English noun phrase in its sentential aspect. Ph.D. dissertation, MIT.

Belazi, H., Rubin, E. J. \& Toribio, J. A. (1994). Code switching and X-bar theory: The Functional Head Constraint. Linguistic Inquiry, 25, 221-237.

Bell, A. (1984). Language style as audience design. Language in Society, 13, 145-204.

Boumans, L. (2001). Searching for syntactic explanations of code switching. Linguistics, 39, 437-453.

Chan, B. H.-S. (1999). Aspects of the syntax, production and pragmatics of code-switching with special reference to Cantonese-English. Ph.D. dissertation, University College London

Chan, B. H.-S. (2004). Aspects of the syntax, pragmatics and production of code-switching - Cantonese and English. New York: Peter Lang.

Chan, B. H.-S. (2005). Code-switching, word order and the lexical/functional category distinction. Ms., University of Macau.

Chini, M. (1995). Genere grammaticale e acquisizione. Aspetti della morfologia nominale in Italiano. Milano: Franco Agnelli.

Chomsky, N. (1981). Lectures on government and binding. Dordrecht: Foris.

Chomsky, N. (1995). The minimalist program. Cambridge, MA: MIT Press.

Chomsky, N. (1998). Minimalist inquiries: The framework. MIT Occasional Papers in Linguistics, 15. [Also in R. Martin, D. Michaels \& J. Uriagereka (eds.), Step by step: Essays on minimalism in honor of Howard Lasnik, pp. 89-155. Cambridge, MA: MIT Press.]

Chomsky, N. (1999). Derivation by Phase. MIT Occasional Papers in Linguistics, 18. [Also in M. Kenstowicz (ed.) (2001), Ken Hale: A life in language, pp. 1-52. Cambridge, MA: MIT Press.]

Chomsky, N. (2001). Beyond explanatory adequacy. Ms., MIT.

Chomsky, N. (2002). On nature and language. Cambridge: Cambridge University Press.

Chomsky, N. (2005). Three factors in language design. Linguistic Inquiry, 36, 1-22.

Chomsky, N. (forthcoming). On Phases. To appear in R. Freidin, C. P. Otero \& M.-L. Zubizareta (eds.), Foundational issues in linguistic theory. Cambridge, MA: MIT Press.

Cinque, G. (1994). Evidence for partial N-movement in the Romance DP. In G. Cinque, J. Koster, J.-Y. Pollock,
L. Rizzi \& R. Zanuttini (eds.), Towards universal grammar: Studies in honor of Richard Kayne, pp. 85-110. Washington DC: Georgetown University Press.

Clyne, M. (1987). Constraints on code-switching: How universal are they? Linguistics, 25, 739-764.

Cornejo, R. (1975). The acquisition of the lexicon in the speech of bilingual children. In P. Turner (ed.), Bilingualism in the Southwest, pp. 141-167. Tucson, AZ: University of Arizona Press.

Coupland, N. (1984). Accommodation at work. International Journal of the Sociology of Language, 4-6, 49-70.

Deuchar, M. \& Quay, S. (2000). Bilingual acquisition: Theoretical implications of a case study. Oxford: Oxford University Press.

Di Sciullo, A.-M., Muysken, P. \& Singh, R. (1986). Government and code-mixing. Journal of Linguistics, 22, 1-24.

Fantini, A. E. (1985). Language acquisition of a bilingual child: A sociolinguistic perspective. Clevedon: Multilingual Matters.

Galasso, J. (2003). The acquisition of functional categories. Bloomington, IN: IULC Publications.

Gardner-Chloros, P. \& Edwards, M. (2004). Assumptions behind grammatical approaches to code- switching: When the blueprint is a red herring. Transactions of the Philological Society, 102, 103-129.

Genesee, F. (1989). Early bilingual development: One language or two? Journal of Child Language, 16, 161-179.

Genesee, F. (2002). Portrait of the bilingual child. In V. J. Cook (ed.), Portraits of the L2 user, pp. 170-196. Clevedon: Multilingual Matters

Giles, H. (1973). Accent mobility: A model and some data. Anthropological Linguistics, 15, 87-105

Giles, H. \& Smith, P. (1979). Accommodation theory: Optimal levels of convergence. In H. Giles \& R. St Clair (eds.), Language and social psychology. Oxford: Blackwell.

Giles, H., Taylor, D. \& Bourhis, R. (1973). Towards a theory of interpersonal accommodation through speech: Some Canadian data. Language in Society, 2, 177-92.

Halmari, H. (1997). Government and codeswitching: Explaining American Finnish, Amsterdam: Benjamins.

Hiraiwa, K. (2005). Dimensions of Symmetry in syntax: Agreement and clausal architecture. Ph.D. dissertation, MIT.

Jake, J. \& Myers-Scotton, C. (1997). Codeswitching and compromise strategies: Implications for lexical structure. International Journal of Bilingualism, 1, 25-39.

Jake, J., Myers-Scotton, C. \& Gross, S. (2002). Making a minimalist approach to code-switching work: Adding the Matrix Language. Bilingualism: Language and Cognition, 5, 69-91.

Joshi, A. K. (1985). Processing of sentences with intrasentential code-switching. In D. Dowty, L. Kartunnen \& A. Zwicky (eds.), Natural language processing: Psychological, computational and theoretical perspectives, pp. 190-204. Cambridge: Cambridge University Press.

Klavans, J. L. (1985). The syntax of code-switching: Spanish and English. In L. D. King \& C. A. Maley (eds.), Selected papers from the XVIIIth Linguistic Symposium on Romance Languages, pp. 213-231. Amsterdam: Benjamins. 
Koehn, C. (1994). The acquisition of gender and number morphology within NP. In Meisel (ed.) (1994a), pp. 2951.

Köppe, R. (1990). Code-Switching: Strategien und Funktionen der Sprachwahl bei bilingualen Kindern. Master's thesis, University of Hamburg.

Köppe, R. (1994). The DUFDE project. In Meisel (ed.) (1994a), pp.15-27.

Köppe, R. (1996). Language differentiation in bilingual children: the development of grammatical and pragmatic competence. Linguistics, 34, 927-954.

Köppe, R. (1997). Sprachentrennung im frühen bilingualen Erstspracherwerb Französisch/Deutsch. Tübingen: Gunter Narr Verlag.

Köppe, R. \& Meisel, J. M. (1995). Code-switching in bilingual first language acquisition. In Milroy \& Muysken (eds.), pp. 276-301.

Kupisch, T. (2001). The acquisition of the DP in French as the weaker language. Working Papers in Multilingualism, 31, $1-34$.

Kupisch, T. (2004). The acquisition of determiners in bilingual German-Italian and German-French children. $\mathrm{Ph} . \mathrm{D}$. dissertation, University of Hamburg.

Kupisch, T., Müller, N. \& Cantone, K. (2002). Gender in monolingual and bilingual first language acquisition: Comparing Italian and French. Lingue e Linguaggio, 1, 107-149.

Lanza, E. (1990). Language mixing in infant bilingualism: A sociolinguistic perspective. Ph.D. dissertation, Georgetown University.

Lanza, E. (1997). Language mixing in infant bilingualism: A sociolinguistic perspective. Oxford: Clarendon Press.

Leopold, W. (1970). Speech development of a bilingual child (4 vols.). New York: AMS Press.

Lindholm, K. \& Padilla, A. (1978). Language mixing in bilingual children. Journal of Child Language, 5, 327-335.

Lipski, J. (1978). Code switching and the problem of bilingual competence. In M. Paradis (ed.), Aspects of bilingualism, pp. 250-264. Colombia, SC: Hornbeam Press.

MacSwan, J. (1997). A minimalist approach to intra-sentential code-switching: Spanish-Nahuatl bilingualism in Central Mexico. Ph.D. dissertation, University of California, Los Angeles.

MacSwan, J. (1999). A minimalist approach to intra-sentential code-switching. New York: Garland.

MacSwan, J. (2000). The architecture of the bilingual language faculty: Evidence from intrasentential code switching. Bilingualism: Language and Cognition, 3, 37-54.

MacSwan, J. (2004). Code switching and linguistic theory. In T. K. Bhatia \& W. Ritchie (eds.), Handbook of bilingualism, pp. 415-462. Oxford: Blackwell.

MacSwan, J. (2005). Codeswitching and generative grammar: A critique of the MLF model and some remarks on "modified minimalism". Bilingualism: Language and Cognition, 8, $1-22$.

Mahootian, S. (1993). A Null Theory of Code-switching. Ph.D. dissertation, Northwestern University.

Mahootian, S. \& Santorini, B. (1996). Code switching and the complement/adjunct distinction. Linguistic Inquiry, 27, 464-479.
Meisel, J. M. (1989). Early differentiation of language in bilingual children. In K. Hyltenstam \& L. Obler (eds.), Bilingualism across the lifespan: Aspects of acquisition, maturity and loss, pp. 13-40. Cambridge: Cambridge University Press.

Meisel, J. M. (ed.) (1990) Two first languages: Early grammatical development in bilingual children. Dordrecht: Foris Publications.

Meisel, J. M. (1994). Code-switching in young bilingual children: The acquisition of grammatical constraints. Studies in Second Language Acquisition, 16, 413-439.

Meisel, J. M. (ed.) (1994a). Bilingual first language acquisition. Amsterdam: Benjamins.

Milroy, L. \& Muysken, P. (eds.) (1995). One speaker, two languages: Cross-disciplinary perspectives on codeswitching. Cambridge: Cambridge University Press.

Moro, M. (2001). The semantic interpretation and syntactic distribution of determiner phrases in Spanish-English code-switching. Presented at the Third International Symposium on Bilingualism (ISB3), 17-24 April, Bristol, UK.

Moyer, M. (1993). Analysis of code-switching in Gibraltarssss. $\mathrm{Ph}$.D. dissertation, Universidad Autònoma de Barcelona, Bellaterra.

Müller, N. (1994). Gender and number agreement within DP. In Meisel (ed.) (1994a), pp. 53-88.

Muysken, P. (1990). Concepts, methodology and data in language research: Ten remarks from the perspective of grammatical theory. Papers for the Workshop on Concepts, Methodology and Data, European Science Foundation Network on Code-Switching, 15-31.

Muysken, P. (1995). Code-switching and grammatical theory. In Milroy \& Muysken (eds.), pp. 177-198.

Muysken, P. (2000). Bilingual speech: A typology of codemixing. Cambridge: Cambridge University Press.

Myers-Scotton, C. (1993). Duelling languages: Grammatical structure in codeswitching. Oxford: Clarendon Press, Oxford.

Myers-Scotton, C. (2001). The matrix language frame model: Developments and responses. In R. Jacobson (ed.), Codeswitching worldwide II, pp. 23-8. Berlin: Mouton de Gruyter.

Myers-Scotton, C. (2002). Contact linguistics: Bilingual encounters and grammatical outcomes. Oxford: Oxford University Press

Myers-Scotton, C. \& Jake, J. L. (1995). Matching lemmas in bilingual competence-performance model: Evidence from intrasentential code-switching. Linguistics, 33, 9811002.

Myers-Scotton, C. \& Jake, J. L. (2001). Explaining aspects of code-switching and their implications. In J. Nicol (ed.), One mind, two languages: Bilingual language processing, pp. 84-116. Oxford: Blackwell.

Namai, K. (2000). Gender features in English. Linguistics, 38, 771-779.

Nartey, J. S. (1982). Code-switching, interference or faddism? Language use among educated Ghanaians. Anthropological Linguistics, 24, 183-192.

Nicoladis, E. \& Secco, G. (2000). Productive vocabulary and language choice. First Language, 20, 3-28. 
Nortier, J. (1990). Dutch-Moroccan Arabic code switching. Dordrecht: Foris.

Paradis, J., Nicoladis, E. \& Genesee, F. (2000). Early emergence of structural constraints on code-mixing: Evidence from French-English bilingual children. Bilingualism: Language and Cognition, 3(3), 245-261.

Pearson, B., Fernandez, S. \& Oller, D. K. (1995). Cross-language synonyms in the lexicons of bilingual infants: one language or two? Journal of Child Language, 22, 345-368.

Petersen, J. (1988). Word-internal code-switching constraints on a bilingual child's grammar. Linguistics, 26, 479-493.

Pfaff, C. W. (1979). Constraints on language mixing: Intrasentential codeswitching and borrowing in Spanish/English. Language, 55, 291-318.

Picallo, M. C. (1991). Nominals and nominalizations in Catalan. Probus, 3, 279-316.

Pizzuto, E. \& Caselli, M. (1992). The acquisition of Italian morphology: Implications for models of language development. Journal of Child Language, 19, 491557.

Poplack, S. (1980). Sometimes I'll start a sentence in Spanish y termino en español: Towards a typology of code-switching. Linguistics, 18, 581-618.

Poplack, S. \& Meechan, M. (1995). Patterns of language mixture: Nominal structure in Wolof-French and FongbeFrench bilingual discourse. In Milroy \& Muysken (eds.), pp. 199-232.

Poplack, S., Wheeler, S. \& Westwood, A. (1989). Distinguishing language contact phenomena: Evidence from FinnishEnglish bilingualism. World Englishes, 8, 389-406.

Radford, A. (1997). Syntactic theory and the structure of English. Cambridge: Cambridge University Press.
Radford, A. (2004). Minimalist syntax: Exploring the structure of English. Cambridge: Cambridge University Press.

Ritter, E. (1991). Two functional categories in noun phrases: Evidence from Modern Hebrew. In S. Rothstein (ed.), Perspectives on phrase structure: Heads and licensing, pp. 37-62. New York: Academic Press.

Romaine, S. (1989). Bilingualism. Oxford: Blackwell.

Sankoff, D. \& Poplack, S. (1981). A formal grammar for codeswitching. Papers in Linguistics, 14, 3-45.

Sankoff, D., Poplack, S. \& Vanniarajan, S. (1990). The case of the nonce loan in Tamil. Language Variation and Change, 2, 71-101.

Sebba, M. (1998). A congruence approach to the syntax of codeswitching. International Journal of Bilingualism, 2, 1-19.

Stenson, N. (1990). Phrase structure, congruence, government and Irish-English code-switching. Syntax and Semantics, 23, 167-192.

Svenonius, P. (2004). On the Edge. In D. Adger, C. de Cat \& G. Tsoulas (eds.), Peripheries: Syntactic edges and their effects, pp. 259-287. Dordrecht: Kluwer.

Trudgill, P. (1986). Dialects in contact. Oxford: Blackwell.

Volterra, V. \& Taeschner, T. (1978). The acquisition and development of language by bilingual children. Journal of Child Language, 5, 311-326.

Weinreich, U. (1964). Languages in contact. The Hague: Mouton.

Woolford, E. (1983). Bilingual code-switching and syntactic theory. Linguistic Inquiry, 14, 520-536.

Received December 8, 2005

Revision received May 17, 2006

Accepted June 6, 2006 